\title{
Option pricing under a Markov-modulated jump-diffusion dividend
}

\author{
Yuanchuang Shan ${ }^{1}$, Haoran $\mathrm{Yi}^{1}$, Xuekang Zhang ${ }^{2}$, and HuiSheng Shu ${ }^{1}$ \\ ${ }^{1}$ Donghua University \\ ${ }^{2}$ Anhui Polytechnic University
}

October 27, 2020

\begin{abstract}
This paper investigates the European option valuation under the condition that the dividend payments follow a Markovmodulated Merton jump-diffusion model. We consider the dividend discount model under real probability measure, the stock price process is then deduced. The regime switching Esscher transform is employed to determine a risk-neutral measure. Finally, we obtain the closed form solution of European option when the dividend announcement time and the dividend payment time are consistent or inconsistent.
\end{abstract}

\section{Hosted file}

OptionpricingunderaMarkov-modulated.pdf available at https://authorea.com/users/370485/ articles/489118-option-pricing-under-a-markov-modulated-jump-diffusion-dividend 